\title{
No caso / In the case
}

\section{Regina de Paula*}

Universidade do Estado do Rio de Janeiro

\section{Resumo}

0 presente artigo discorre sobre o processo artístico da autora, tratando especificamente das séries Não habitável e Sobre a areia. O texto destaca a importância de viagens (Nova York e Jerusalém), bem como daquilo que ela denomina como "acontecimento" para esses trabalhos.

\section{Palavras-Chave}

processo; acontecimento; lugares; narrativa.

\section{Abstract}

The article analyzes the artistic process of the author, in particular of the series Nonhabitable and On Sand. The text highlights the importance of travel (New York and Jerusalem), as well as of what the artist denominates "happening" in these works.

\section{Keywords}

process; happening; places; narrative.

\footnotetext{
* Artista, professora adjunta do Instituto de Artes da Universidade do Estado do Rio de Janeiro/Uerj. Dentre suas exposições recentes destacam-se as individuais "E fiquei de pé sobre a areia", Galeria Mercedes Viegas (Rio de Janeiro, 2014) e "Miragens", Projeto Cofre, Casa França Brasil (Rio de Janeiro, 2009); e as coletivas "Há escolas que são gaiolas. Há escolas que são asas", no Museu de Arte do Rio - MAR (2014); "Três artistas", Galeria Paradigmas (Barcelona, 2011), "Realidades do desenho contemporâneo brasileiro", Sesc Pinheiros (São Paulo, 2010), dentre outras.
} 


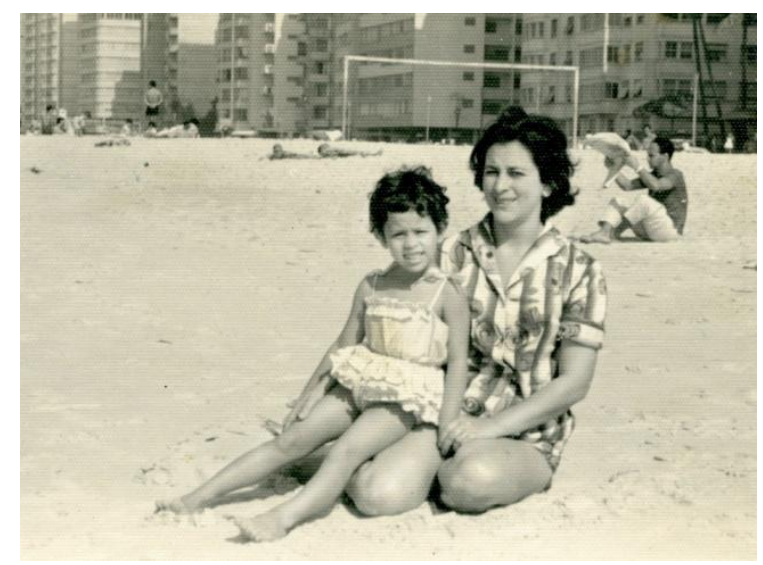

Fig.1. Regina de Paula e sua mãe na praia de Copacabana nos anos 60; fonte: autora.

No caso é um acontecimento, um evento, algo que despenca. A fruta quando está madura cai do pé. Um trabalho quando encarna também cai. Falarei, então, de duas encarnações e algumas derivações - a da série Não habitável e, especialmente, da mais recente, que agora (talvez provisoriamente) a estou denominando Sobre a areia. A primeira diz respeito a trabalhos desenvolvidos a partir de determinados espaços desde 1999 e que resultaram em fotografias, desenhos e um vídeo. Não habitáveis são espaços de passagem, corredores, escadas, capturados geralmente em período de inatividade, ou seja, vazios. Não habitável foi o tema de minha tese de doutorado, portanto, um assunto, de certo modo, já decifrado. 


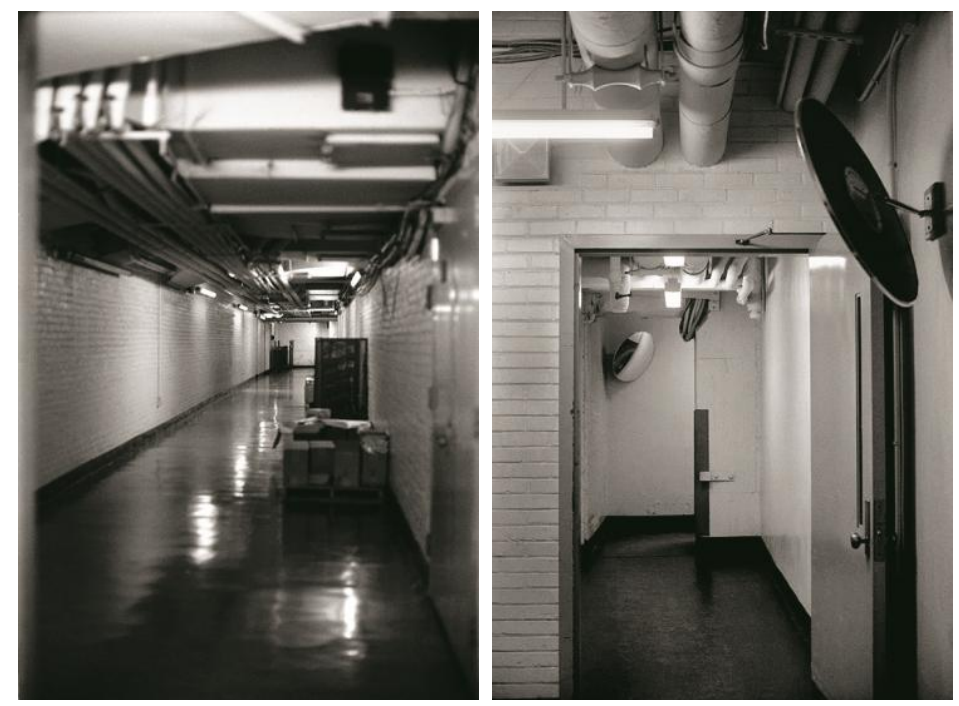

Figs.2-3.Sem título, da série Não habitável (NY), 1999, fotografia; 150 x 101cm (cada); fonte: autora.

A série Sobre a areia é mais recente, ainda um tanto enigmática e espero que continue assim por um bom tempo, pois se decifro, já era, não faço mais, se é que você me entende. Vou, então, ficar na órbita, pois não posso deixar quieto, tenho de escrever, é disso que se trata aqui. Começarei esclarecendo, na medida do possível, como surgiu o que agora já chamo de série. Digamos que teve um começo, um ponto de partida. Eu posso dizer que foi num certo dia de agosto de 2012, quando fui jantar com minha prima e ela me falou de sua próxima viagem a Jerusalém. Foi então que, sabe-se Deus por que, decidi que iria também. $E$ fui. Parecia que não era para ser; a universidade entrou em greve, a viagem que tinha uma data conveniente deixou de ter, conflitos na faixa de Gaza. Tudo isso me fez hesitar, e muito. Eu queria desistir e comecei até a buscar desculpas, tipo: o prazo para publicação de minha viagem no Diário Oficial (requisito para docentes viajarem legalmente) estava expirando e eu não queria viajar sem garantias, mas a secretária do meu departamento, que se chama Fátima, e nem está mais lá, me disse, "professora vamos dar um jeito, a senhora tem que ir, se não for, vai atrasar sua pesquisa". Ah, gostei quando ela falou "pesquisa", então eu tinha uma pesquisa e nem sabia. Eu tenho essa característica, depois que decido, não consigo desistir, mesmo querendo. Vai entender. Decisões podem então ser camisas de força. Parecem sufocantes, mas também podem ser "do bem". 
Eu já falei um pouco sobre 0 assunto em outro artigo, mas vou retomar o tema. 0 que de imediato me atraiu nessa viagem foi pensar que ia para o deserto, para a paisagem arenosa. Não é de agora que trabalho com areia e essa matéria sempre teve para mim relação com a paisagem. De imediato, posso apontar que as duas séries em questão surgiram do meu encontro com certos lugares: com Jerusalém e, nas primeiras fotos da série Não habitável, com Nova York, quando estudava na Columbia University. Acontece que eu queria estudar na Califórnia e por contingências mudei de rumo. Por outro lado, nunca havia pensado em ir a Israel, mas o encontro com a Ana, minha prima, despertou algo que me levou a essa viagem. No caso.

Essas séries foram geradas a partir de meu encontro com lugares fora do meu hábitat, o Rio de Janeiro. As viagens são extremamente importantes para o meu trabalho, detonadoras de um processo imprevisível, mas nem todas as viagens proporcionam alguma inspiração. É que algo precisa vir ao encontro, como se 0 novo lugar despertasse alguma coisa que já estava lá e acho que isso tem a ver com a paisagem e também com o sentimento de não pertencimento, de solidão, que faz com que tudo fique intenso, tátil. Félix Guattari diz que "percepções atuais do espaço podem ser 'duplicadas' por percepções anteriores" (GUATTARI, 1992: 155). Em Nova York, a sensação que tive nos corredores que fotografei foi a de um sentimento de certa desorientação, uma apreensão. Segundo Jentsch, citado por Freud em seu famoso texto sobre o sentimento do "estranho", "Quanto mais orientada a pessoa está, no seu ambiente, menos prontamente terá a impressão de algo estranho em relação aos objetos e eventos nesse ambiente" (FREUD, 1919: 277), mas Freud vai além e após um longo passeio etimológico conclui que a palavra estranho, unheimlich em alemão, é ambivalente, remete também ao conhecido, familiar (1919: 282). Os corredores da série Não habitável, mesmo não sendo conhecidos, são reconhecíveis como espaços de passagem e, assim, o sujeito pode ser transportado para outro lugar. Jerusalém, por seu turno, é a cidade de todos nós, no Ocidente. Pode-se, então, dizer que a escolha desses lugares tem relação com um estranhamento pela via do "(re)conhecimento". 
A minha ida a Jerusalém teve particularidades já no percurso. Meu voo, pela Alitália, fazia escala em Roma e no aeroporto os viajantes que seguiriam para Israel foram encaminhados para uma sala, numa área bem vazia, que só tinha uma lojinha chinfrim. Senti como se estivéssemos isolados, e a coisa ficou realmente estranha. Logo, dois grupos se formaram: judeus religiosos e evangélicos ricaços, todos totalmente fechados entre os seus. Uma "galera" pouco atraente, mas 0 mundo de repente ficou assim, composto por duas tribos e eu, ali, avulsa. No primeiro grupo, os homens logo se equiparam com aquelas caixinhas intrigantes e tirinhas pretas, chamadas tefilin e, de fato, incríveis, e foram rezar voltados para a parede, balançando a cabeça. Já suas mulheres, algumas até do tipo que poderiam ser minhas amigas, mas obviamente nem me enxergavam, confraternizavam. Nem preciso dizer, eu me senti totalmente legião estrangeira. De fato, comecei a sentir um pouco de medo, uma intuição de que coisa boa não ia "rolar". Mas, estranho, estranho mesmo, eu me sentia suspeita, sabe-se lá do quê, como se tivesse que disfarçar não sei o quê. Eu tinha então um plano sinistro e nem sabia. Comecei a sentir uma espécie de síndrome de Estocolmo. Eu realmente estava só e tive uma necessidade incrivel de me conectar. Tentei conversar com os evangélicos, já que 0 grupo era de brasileiros, mas não me deram trela, já o outro grupo estava num universo totalmente paralelo ou eu é que estava. Avistei uma jovem riponga, um tipo mais alternativo, com uma criança meio sujinha, ambas pareciam bem felizes, tipo de dar inveja, então fui me enturmar com a moça. Ela era de São Paulo, me falou que casou e foi viver num kibutz, parecia aquele tipo de pessoa que teve a sorte de encontrar seu lugar no mundo, bem o contrário do que eu sentia ali. Aliás, poucas vezes usufrui daquele sentimento "oceânico", "de algo sem limites, sem barreiras", que Freud descreve em O mal-estar na cultura (FREUD, 2010: 42). Mas a moça parecia desfrutar dessa bem-aventurança. Ao chegar ao aeroporto Ben Gurion, passei por percalços na imigração, "tipo" ter de esperar e responder a várias perguntas de uma policial que depois me encaminhou para outra dupla de policiais, enquanto a turma toda do meu voo passou tranquilamente pela imigração. Logo eu era suspeita. 
Foi nesse clima, com a sensação de não saber onde estava pisando, que começou a minha estada. Jerusalém como alguém disse é uma "Disney das religiões", a Cidade Antiga é dividida em vários bairros: judeu, árabe, cristão e armênio, mas diferentemente do parque temático americano, tem uma atmosfera histórica e religiosa incrível e você pode realmente entrar numa trip. Essa, aliás, já foi até catalogada como "síndrome de Jerusalém", surto místico que acomete turistas pirados ao visitarem lugares bíblicos. Mal sabia eu que seria também, ao meu modo, acometida pela síndrome.

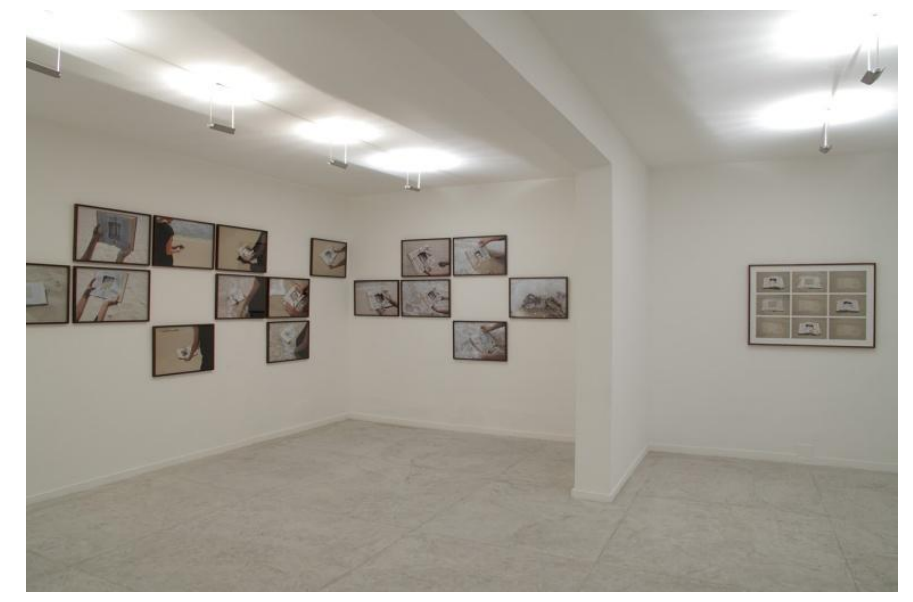

Fig.4. Vista parcial da exposição "E fiquei de pé sobre a areia", 2014. Galeria Mercedes Viegas Arte Contemporânea, Rio de Janeiro; foto: Wilton Montenegro.

A minha primeira individual pós-viagem, ou seja, pós-aquilo-que-chamei-desíndrome, foi "E fiquei de pé sobre a areia", na Galeria Mercedes Viegas, no Rio de Janeiro, em 2014. Depois que as ideias começaram a "despencar". A areia está presente em minha poética desde os anos 90, quando retornei de Nova York. Nesse período, a minha vida não era nada estável, eu tinha de me instalar, procurar trabalho e por aí vai. Havia também aquela sensação de estranhamento que as viagens também no retorno proporcionam, com contrastes de gente, luz, sons, cheiros. De todo modo, eu tinha muito tempo livre e, como sempre fui de caminhar, parte do meu dia era pura "flanação" e eu ficava pasma com a relação da natureza com a cidade no Rio de Janeiro, com essa paisagem em que o homem é praticamente coautor da natureza. Uma ideia vaga me atormentava: eu queria fazer um trabalho que incorporasse de algum modo a cidade. Foi assim que, de tanto 
caminhar pela orla e da observação do trabalho dos escultores de areia, comecei a retirar da praia matéria para o meu trabalho, no caso, areia. Foi preciso um bom tempo para os trabalhos surgirem. Um dos primeiros resultados foi uma construçãoruína (Sem título, 1997), com tijolos de areia, em que três colunas se erguem e no topo delas equilibra-se uma pequena mesa de madeira, encontrada também numa praia, que apoia um castelo também de areia. A areia, desde então, tinha essa associação com a instabilidade, com a poética da precariedade.



Fig.5. Sem título, 1997, tijolos de areia e mesa de madeira, 92 × 225 × $310 \mathrm{~cm}$ (variável); foto: Wilton Montenegro.

$\mathrm{Na}$ instalação Miragens (2012), realizada no pequeno recinto que um dia foi o cofre da Alfândega, na Casa França-Brasil, preenchi grande parte do local com areia, contida por uma placa de acrílico curva, seguindo o raio da abertura da porta que abria para dentro, deixando espaço para, no máximo, três observadores. A areia, sempre instável, não cessava de mover-se, formando fissuras, desenhos, enquanto a superfície lançava o olhar para longe, prenunciado a paisagem desértica que logo eu iria encontrar. 

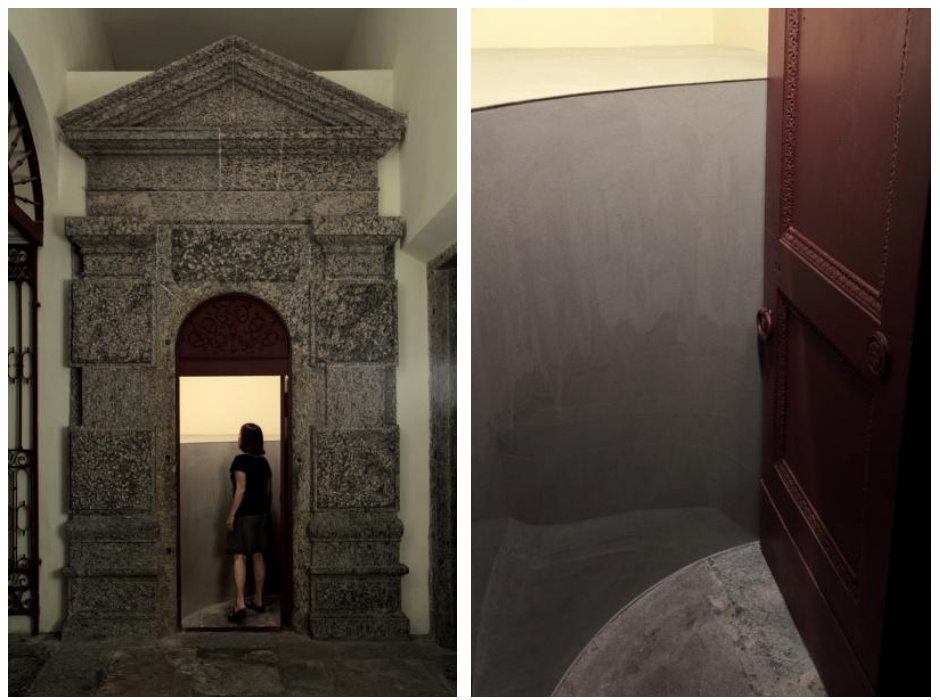

Fig.6-7. Miragens, 2012, Projeto Cofre / Casa França-Brasil, Rio de Janeiro, areia contida por placa de acrílico, foto: Wilton Montenegro.

Alguns meses após a viagem a Jerusalém, estava com a ideia fixa em fazer algum trabalho com livros, o desejo era totalmente abstrato e eis que uma ideia encarna, cai: eu visualizo uma bíblia aberta ao meio, com parte de seu centro "escavado" geometricamente, na forma de um quadrado, quase um cubo negativo, preenchido com areia de praia, matéria que genericamente é a mesma da paisagem bíblica. No conto "Livro de areia", do escritor argentino Jorge Luis Borges, um vendedor de bíblias bate à porta do personagem narrador com 0 intuito de vender-lhe outra publicação, intitulada Livro de areia, "porque nem o livro nem a areia têm princípio nem fim" (BORGES, 1999: 80). A areia é em si mesma uma quase-metáfora. Há pouco me deparei com uma fotografia da minha infância na praia de Copacabana, recostada em minha mãe, ambas com o cenho franzido, certamente pelo sol, mas não deixo de pensar em minha possível perplexidade infantil, com a vida pela frente, embora nessa foto eu me escape. Lembro-me do dito popular: "é muita areia para o meu caminhãozinho". Como me angustiei na infância, na escola, tentando organizar em minha mente toda a história que a professora nos ensinava, buscando uma sequencialidade, sentindo como se tal fosse uma obrigação, e ficava perturbada quando um fato novo, que não pertencesse à versão oficial confundisse a minha ignorância. Talvez por isso 0 desgosto com as fantasias que minha mãe me preparava para o Carnaval: baiana à la Carmen Miranda, índia! Tive uma de pierrô, mas achei um tanto vago, Como pode? Eu queria ser grega, bailarina ou, no 
máximo do exotismo, odalisca. Mas no "Livro de areia", nenhuma página é a primeira, "nenhuma, a última" (BORGES, 1999: 81).

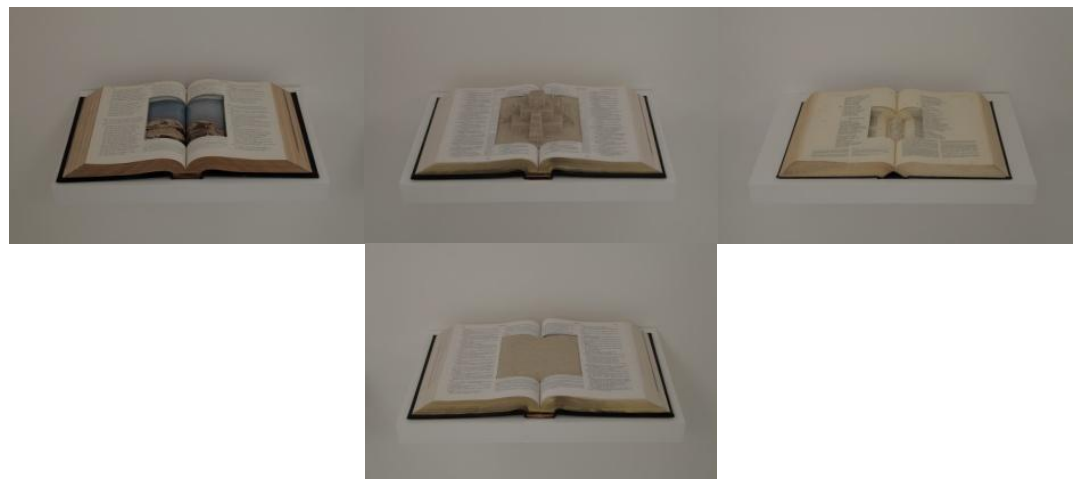

Figs. 8-11.Da esquerda para a direita:

Bíblia (paisagem), 2014, Bíblia com recorte, 47 x $29 \mathrm{~cm}$

Bíblia (templo de areia), 2014, Bíblia em espanhol com recorte, areia e templo de areia com impermeabilizante, $29 \times 46 \mathrm{~cm}$

Bíblia (cubo negativo), 2014, Bíblia de Jerusalém com recorte, 27,5 x $42 \mathrm{~cm}$

Bíblia (areia), 2014, Bíblia com recorte e areia, 28,5 x 49 cm; fotos: Wilton Montenegro

Realizei mais três intervenções em outros exemplares da Bíblia, a partir da mesma operação de recorte. Em uma deixei o vazio não preenchido, em outra revelei uma das ilustrações, uma paisagem do mar da Galileia e, finalmente, para a terceira tive outra epifania. No caso. Um dia, em minha última viagem à Nova York, entrei numa loja de brinquedos e encontrei um conjunto de formas de plástico para brincar na praia, dessas de moldar areia e, dentre elas, uma no formato de uma pirâmide précolombiana. Nela moldei uma pirâmide com argamassa de areia e que permaneceu por muito tempo pousada, quieta, na estante, entre meus livros. Eis que de repente olho para essa miniatura, em seguida para a Bíblia, e algo despenca: vejo que a pequena construção arenosa encontrou o seu lugar. Compro uma Bíblia em espanhol, faço o recorte geométrico, encaixo a pirâmide e preencho o espaço restante com areia, aludindo assim à catequese pré-hispânica das Américas.

Recentemente, remexendo a bagunça de meu ateliê-casa, encontrei um envelope com o material que foi recortado dessas Bíblias, trechos incompletos, em função da natureza do recorte. Comecei a separar algumas frases, unindo partes e fui criando 
uma narrativa em que passagens da Bíblia se misturam, cobrindo linhas de um desenho realizado a partir do traçado geométrico e labiríntico da cerâmica marajoara.



Fig. 12. Série Marajoara, 2015, colagem sobre tela de linho, 59 x $53 \mathrm{~cm}$; foto: Wilton Montenegro.

À guisa de conclusão, posso dizer que a série Sobre a areia começou a ser gerada desde o meu olhar para a paisagem arenosa de Copacabana ao retornar de Nova York para o Rio de Janeiro, no final de 1992, e que Miragens é um evidente prenúncio. Os trabalhos começam a acontecer depois de minha viagem a Jerusalém e a partir de então começaram a gerar vários desdobramentos. As formas labirínticas dos desenhos marajoaras, por exemplo, apontam agora para novos caminhos e reafirmam a poética dos trabalhos. $O$ labirinto, segundo Dennis Hollier (1992: 58), não é um lugar seguro, é o espaço onde as oposições se tornam complicadas, perigosas. Para o personagem de Borges, no conto "Os dois reis e os dois labirintos", o deserto é um labirinto sem paredes, "... onde não há escadas a subir, nem portas a forçar, nem cansativas galerias a percorrer, nem muros que te vedem os passos" (BORGES, 1998: 676). 
Nos textos extraídos da Bíblia, nos meus labirintos marajoaras, as frases se misturam, criando outro labirinto, de palavras, que derivam dos restos das "escavações". As escavações também são labirínticas, adentrar os corredores não habitáveis é escavar, cortar a Bíblia, interromper, perder e achar é labiríntico. Os textos descartados se reencontram no labirinto, ali se encontram e se perdem, e não tem mais como voltar. Do labirinto não se retorna.

E fiquei de pé sobre a areia, 12 de outubro de 2015.

\section{Referências}

BORGES, Jorge Luis. "O livro de areia" [1975]. In: Obras completas. Vol. 3. Trad. Ligia Morrone Averbuck. São Paulo: Globo, 1999, p.79-83.

. "Os dois reis e os dois labirintos" [1949]. In: Obras completas. Vol.1. Trad. Flavio José Cardozo. São Paulo: Globo, 1998, p.676.

FREUD. O "estranho" [1919]. In: Edição standard brasileira de obras psicológicas completas de Sigmund Freud. v. XVII. Trad. do alemão e do inglês sob a direção geral e revisão técnica de Jayme Salomão. Rio de Janeiro: Imago, 1970, p. 270-315.

O mal-estar da cultura. Trad. Renato Zwick. Porto Alegre: L\&PM, 2010.

GUATTARI, Félix. Caosmose: um novo paradigma estético. Trad. Ana Lúcia de Oliveira e Lúcia Cláudia Leão. São Paulo: 34, 1992.

HOLLIER, Denis. Against architecture: the writings of Georges Bataille. Trad. Betsy Wing. Cambridge- -London: The MIT Press, 1992 [1974]. 